\title{
ACS \\ Through-Wall Mass Transport as a Modality for Safe Generation of Singlet Oxygen in Continuous Flows
}

Katherine S. Elvira, ${ }^{\dagger}$ Robert C. R. Wootton, ${ }^{*}{ }^{\dagger}$ Nuno M. Reis, ${ }^{\dagger}$ Malcolm R. Mackley, ${ }^{\S}$

and Andrew J. deMello*,

${ }^{\dagger}$ Department of Chemistry and Applied Biosciences, Institute for Chemical and Bioengineering, ETH Zürich, Wolfgang-Pauli Strasse 10, Zürich, 8093, Switzerland

${ }^{\ddagger}$ Department of Chemical Engineering, Loughborough University, Loughborough LE11 3TU, United Kingdom

${ }^{\S}$ Department of Chemical Engineering and Biotechnology, New Museums Site, Pembroke Street, Cambridge CB2 3RA, United Kingdom

\section{Supporting Information}

ABSTRACT: Singlet oxygen, a reactive oxygen species, has been a basic synthetic tool in the laboratory for many years. It can be generated either through a chemical process or most commonly via a photochemical process mediated by a sensitizing dye. The relative paucity of singlet oxygen employment in fine chemical industrial settings can be attributed to many factors, not least the requirement for excessive quantities of oxygenated organic solvents and the dangers that these represent. Microcapillary films (MCFs) are comprised of multiple parallel channels embedded in a plastic film. In this study, MCFs are employed as flow reactor systems for the singlet oxygen mediated synthesis of ascaridole. No gaseous oxygen is supplied directly to the reaction, rather mass transport occurs exclusively through the

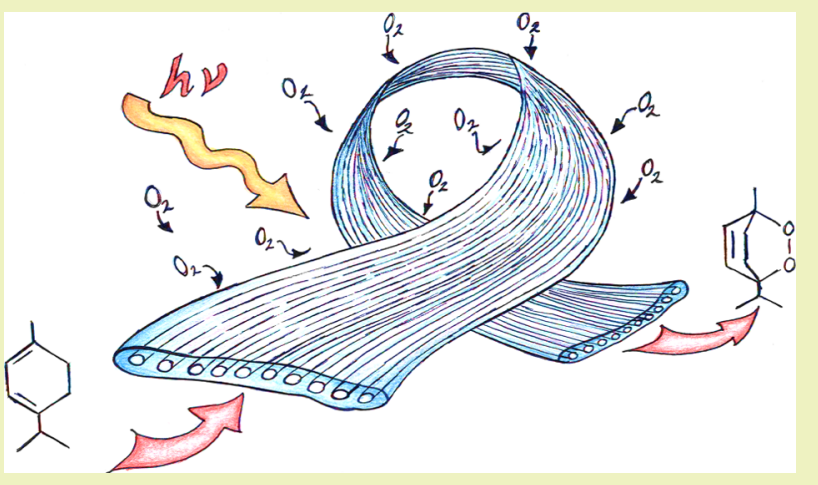
reactor walls. The rate of production of ascaridole was found to be strongly dependent on the partial pressure of oxygen present within the reaction system. This methodology significantly simplifies reactor design, allows for increased safety of operation, and provides for space-time yields over 20 times larger than the corresponding bulk synthesis.

KEYWORDS: Microcapillary Film (MCF), Ascaridole, Photo-Oxidation, Synthesis, Microfluidics, Microreactor Technology, Flow Chemistry

\section{INTRODUCTION}

Singlet oxygen has found increasing application in biomedical systems, whether as an antimicrobial treatment for water ${ }^{1}$ or as part of a targeted photodynamic therapy for antimicrobial or cancer treatments. ${ }^{2}$ However, it is disappointing that singlet oxygen processes are not more widely used in industrial settings, since these reactions are extremely clean and green because, instead of using reactive halogen compounds, oxometalates, or other stoichiometric oxidants, the catalytic process may use air as the oxidant. To this end, much recent research has been focused on finding a safer environment for performing such reactions. ${ }^{3}$

Dye-sensitized singlet oxygen generation has been used for the production of dioxetanes and other endoperoxide species on the benchtop ${ }^{4}$ despite the industrial application of this process being less widespread. ${ }^{5}$ Sensitizing dyes for the formation of singlet oxygen vary from the most venerable (Rose Bengal and methylene blue have been in use since the $\left.1950 s^{6}\right)$ through azomethines ${ }^{7}$ and others ${ }^{8}$ to those from the porphyrin family. ${ }^{9}$ Sensitizer selection depends on the solvent used more than any other factor because of the necessity for the sensitizer to be soluble in the reaction solvent.

Microfluidic reactor chemistry is a field with particular relevance to catalytic and photocatalytic systems, which is currently making the transition from a laboratory tool to industrial methodology. ${ }^{10,11}$ Indeed, this modality has previously been used to generate and process singlet oxygen by ourselves $^{3}$ and others. ${ }^{12,13}$ However, to date, the key problem with these approaches relates to oxygen mass transport. In single microfluidic reactors, combining flows of oxygen and reaction mixtures is not challenging. However when the reaction is scaled out, necessitating the use of multiple channels, the problem of distribution of gas and liquid becomes a major issue. Put simply, the complex flow regime which asserts itself in gas-liquid microchannel flows ${ }^{14}$ makes scaleout a difficult prospect if uniform reaction times and mass transport profiles are to be maintained over extended periods of time.

Received: September 10, 2012

Revised: December 19, 2012 
Microcapillary films (MCFs) ${ }^{15}$ (Figure 1) provide an attractive alternative to planar microfluidic formats, with

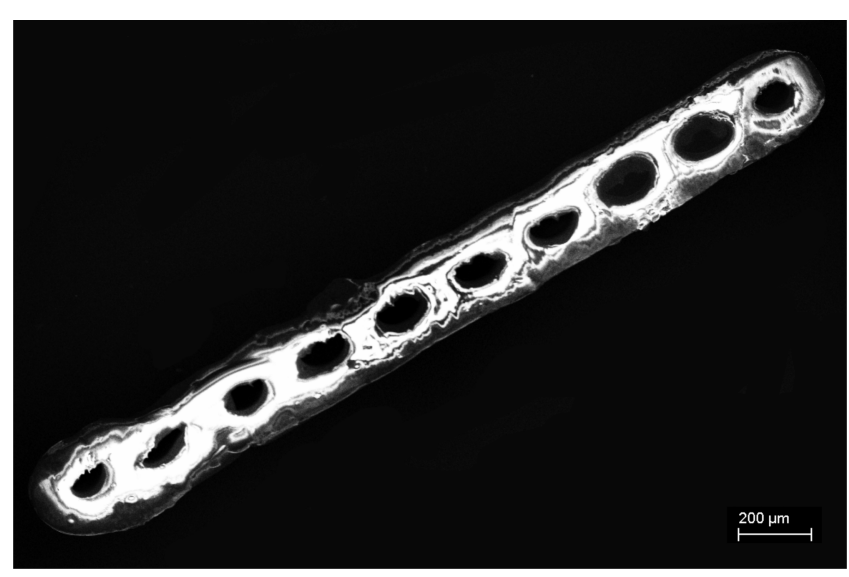

Figure 1. Scanning electron micrograph showing a side view of the FEP MCFs. The image was taken at $171 \times$ magnification. The average hydraulic diameter of each capillary is $104.2 \mu \mathrm{m} \pm 10.6 \mu \mathrm{m}$ with an average wall thickness of $61.5 \mu \mathrm{m} \pm 17.1 \mu \mathrm{m}$.

advantages that include the low-cost production of long lengths of MCFs. ${ }^{15}$ In addition, fluorinated ethylene propylene (FEP) MCFs are optically flat on the outside, have a refractive index close to that of water $(\approx 1.34)$, and have high transmittance in ultraviolet and visible regions of the electromagnetic spectrum. All these features provide for excellent light penetration through assemblies of MCFs. ${ }^{16}$ In recent times, planar arrays of MCFs have been used as solar heat collectors, ${ }^{17}$ as low-cost formats in quantitative immunosorbant assays, ${ }^{16}$ and functionalized to perform fast cation-exchange separation of proteins. ${ }^{18}$
Furthermore, several organic syntheses have also been performed in MCFs. ${ }^{19}$

Fluoropolymers exhibit appreciable gas permeability. ${ }^{20}$ To date, the utility of MCFs in mediating the transport of gases has not been investigated, but we believe they have the potential to be an attractive modality for heterogeneous reactions where the addition of gas may either be dangerous or in the case of coflowing aqueous and gaseous reagents may have detrimental effects on the synthesis. To investigate the utility of MCFs in this respect, we report the synthesis of ascaridole from $\alpha$ terpinene (Scheme 1A) as the model system for our investigation of through-wall mass transport of oxygen in MCF fluoropolymer capillary reactors. Ascaridole is a rare example of a naturally occurring, thermally stable endoperoxide. $^{21}$ The synthesis of ascaridole through singlet oxygen photoaddition has a long history and has been extended to related structures, which have antimalarial properties. ${ }^{22}$ Rose Bengal is a well-characterized sensitizer, commonly used in singlet oxygen chemistry. ${ }^{23}$

As an aside, it should be noted that Kreutz et al. ${ }^{24}$ recently demonstrated the use of the permeability of Teflon tubing to allow the diffusion of oxygen and methane into droplets containing a range of different catalysts for the oxidation of methane to methanol. This work is remarkable in that the authors used what is commonly considered a problem, namely, the porosity of the microchip material, as a mediator for their synthesis. The synthesis was performed in single Teflon-PFA tubing encased in a steel tube, which was used to provide the gases and is a setup that makes scaleout a more complicated process.

Scheme 1. (A) Synthesis of Ascaridole (3) from $\alpha$-Terpinene (1) with Singlet Oxygen Created Using Rose Bengal (2) ${ }^{a}$ (B) Mechanism for Synthesis of $p$-Cymene from $\alpha$-Terpinene Occurs via a Single Electron Transfer Reaction with Triplet Ground State Oxygen ${ }^{b}$<smiles>CC1=CC=C(C(C)C)CC1</smiles>

(1)

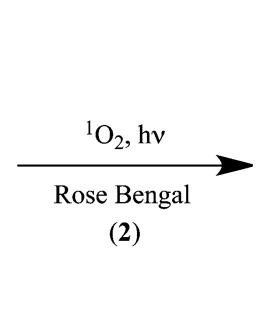

(2)<smiles>CC(C)C12C=CC(C)(CC1)OO2</smiles>

(3)<smiles>Cc1ccc(C(C)C)cc1</smiles>

(4)

(B)

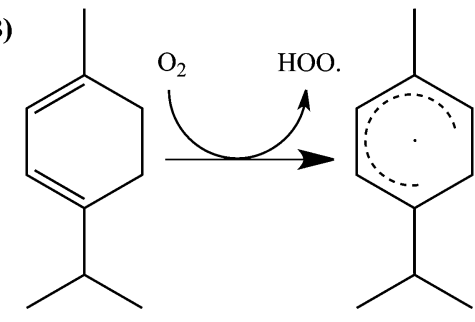<smiles>CC(=O)C1=CC(C)=CCC1([O-])C(C)C</smiles><smiles>Cc1ccc(C(C)C)c(C(=O)O)c1</smiles>

(1)

\footnotetext{
${ }^{a}$ A possible side product of the reaction is $p$-cymene (4). A maximum yield for the conversion of $\alpha$-terpinene to ascaridole is achieved when the reaction is illuminated at $570 \pm 5 \mathrm{~nm}$.

${ }^{b}$ However, although it is the main byproduct in the synthesis of ascaridole, $p$-cymene was not detected in the MCFs.
} 


\section{RESULTS AND DISCUSSION}

Oxygen mass transport is assumed to be the limiting factor in a singlet oxygen $[4+2]$ cycloaddition process. Accordingly, the pressure of oxygen applied to the exterior of the MCFs was varied as a means of controlling the rate of through-wall mass transport of oxygen. The microflow system used in this study consisted of a MCF produced from FEP containing 10 parallel microcapillaries. Degassed reagents for the synthesis of ascaridole were delivered to the MCFs. To ascertain the degree of gas transport across the MCF walls, the yield of ascaridole was measured at different reagent residence times and pressures of oxygen. Bulk synthesis of ascaridole was used to secure pure samples of ascaridole (3) and $p$-cymene (4) (the major byproduct) for use as gas chromatography (GC) standards, and calibration plots for $\alpha$-terpinene, $p$-cymene, and ascaridole were created by performing serial dilutions of the pure samples. The calibration curves were used to determine the concentration of each analyte in the samples collected from the FEP MCFs (experimental details are provided in the Supporting Information).

Initial experiments performed in MCFs with a wall thickness of $\sim 160 \mu \mathrm{m}$ showed minimal conversion, even at relatively high applied pressures $(65.0 \mathrm{psi})$. On varying the MCF wall thickness $(61.5 \mu \mathrm{m} \pm 17.1 \mu \mathrm{m})$ to reduce resistance to mass transport, conversion of $\alpha$-terpinene to ascaridole was observed. As the applied external pressure of oxygen was increased from 32.5 to $65.0 \mathrm{psi}(224080$ to $448159 \mathrm{~Pa})$, an increase in reaction rate was detected (Figure 2).

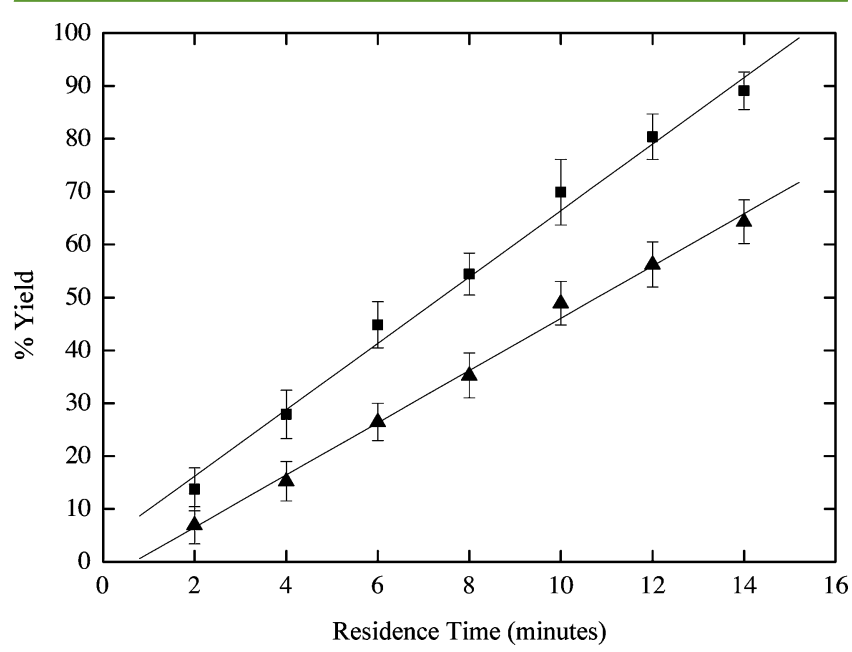

Figure 2. Seven different reaction times (average residence time of the reagents in the MCFs) were sampled, and the yield of ascaridole was

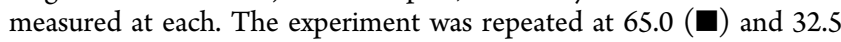
psi $(\boldsymbol{\Delta})$. The percentage yield of ascaridole increases linearly with average residence time at both pressures, with the yield increasing with pressure.

The production of singlet oxygen by sensitizer dyes is generally agreed to follow the mechanism outlined in the unitary equations in Scheme $\mathrm{S1}^{25}$ in the Supporting Information. Here, $\varphi$ is the quantum efficiency of the excitation process, and $k$ in each case represents the rate coefficient associated with the unitary process indicated. ${ }^{25} Q$ is a quenchant (i.e., any molecule capable of accepting energy from singlet oxygen via a nonreactive pathway in order to produce triplet oxygen), "Sens" is the sensitizer dye and "Sub" represents the substrate molecule, in our case $\alpha$-terpinene. The first three steps are often conflated into a single figure, $\kappa$, which represents the quantum efficiency of singlet oxygen production. This equation is expressed in terms of the product quantum yield, $\phi$, and is given by the following equation: ${ }^{26}$

$$
\Phi=\kappa \frac{k_{4}[\mathrm{Sub}]}{k_{3}+k_{4}[\mathrm{Sub}]}
$$

where $\kappa$ is the quantum efficiency for the production of singlet oxygen, [Sub] is the concentration of $\alpha$-terpinene, and $k_{3}$ and $k_{4}$ are the rate coefficients taken from the unitary equations in Scheme S1 of the Supporting Information. The quantum efficiency defines how many incident photons produce an excited state product. The implication of this equation is that in situations where $[\mathrm{Sub}]$ is sufficiently high, the reaction will be zeroth order with respect to $\alpha$-terpinene, with a rate that depends only on $\kappa . \kappa$ is generally stated as depending only on sensitizer concentration; however, this is because in most experimental systems the concentration of triplet oxygen is held at a steady equilibrial state close to saturation. The reaction time courses shown in Figure 2 do indeed show zeroth order kinetics, with a slope equivalent to $\kappa$. This is borne out by comparing the rate of consumption of $\alpha$-terpinene with the rate of production of ascaridole (Figure 3), which also shows pseudo linear forms. However, at different applied pressures of oxygen, the slope varies despite [Sens] remaining constant. This is because the oxygen in our system is unlikely to reach saturation at any time before the completion of the reaction, and so the oxygen concentration is a defining factor in the magnitude of $\kappa$. In addition, because of the inherent reactivity and short half-life of singlet oxygen, there is negligible diffusion of singlet oxygen out of the channel. The measured rates at 65 and $32.5 \mathrm{psi}$ were $2.94 \times 10^{-4} \mathrm{~mol} / \mathrm{s}$ and $1.57 \times 10^{-4} \mathrm{~mol} / \mathrm{s}$, respectively, confirming a strong relationship between oxygen concentration and $\kappa$.

For the bulk synthesis of ascaridole, $p$-cymene is almost always observed as a major byproduct. This is formed not as a result of singlet oxygen oxidation but rather as a result of a single electron transfer reaction with triplet ground state oxygen (Scheme 1B). ${ }^{27}$ In MCF reactors, we found no detectable production of $p$-cymene. This suggests that the concentration of triplet oxygen is never high enough to promote this reaction over the desired singlet pathway, implying a high irradiation efficiency compared to bulk reactor formats. Additional experiments showed that increasing or decreasing illumination had little effect on the yield of ascaridole. Indeed, even relatively low ambient light conditions allow for efficient transformation. This again underlines the rate of mass transport of oxygen, not light intensity, as the limiting factor in this reaction series.

The data gathered in these experiments allow an approximate value for the diffusion coefficient of oxygen in FEP to be calculated. Assuming an instantaneous reaction and that all the oxygen transported through the FEP wall reacts with $\alpha$ terpinene, for one mole of oxygen transported through the wall, one mole of product is formed. Therefore, the diffusion coefficient of oxygen in FEP (with a wall thickness of $61.5 \mu \mathrm{m}$ ) can be approximated as 0.00442 and $0.00273 \mathrm{mols} \mathrm{s}^{-1} \mathrm{~m}^{-2}$ at 65 and 32.5 psi, respectively.

At a residence time of $14 \mathrm{~min}$, yields in excess of $90 \%$ ascaridole were consistently achieved. For a single, $5 \mathrm{~m}$ long, 10 channel MCF used in these experiments, the maximum utilized flow rate was $196.3 \mu \mathrm{L} / \mathrm{min}$, defining a production capacity of 

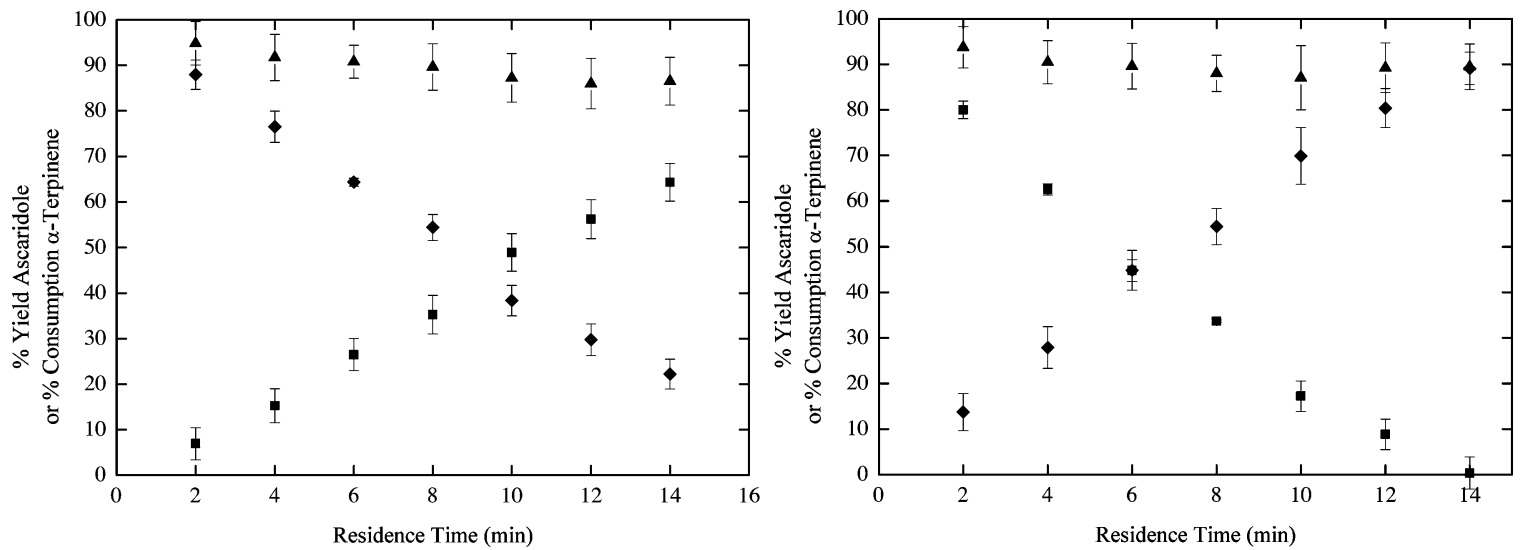

Figure 3. Comparison of the percentage yield of ascaridole $(\boldsymbol{\square})$ and the consumption of $\alpha$-terpinene $(\bullet)$ at different residence times show pseudo linear forms. The sum of the data for ascaridole and $\alpha$-terpinene at each point are plotted $(\boldsymbol{\Delta})$ to show that most of the reaction mixture is accounted for by these chemicals. The graph on the left shows data at $32.5 \mathrm{psi}$, and the graph on the right shows data for 65 psi.

$3.98 \times 10^{-4} \mathrm{~g} / \mathrm{min}$. However, the MCF reactor is extremely easy to scale out, and so the eventual production capacity of this single autoclave would be $8.84 \mathrm{mg} / \mathrm{min}$. This equates to processing $3.5 \mathrm{~mL}$ per minute of fluid. The space-time yield for the MCF synthesis (at maximum conversion) is $6.36 \%$ per minute, which compares extremely favorably with $0.28 \%$ per minute for the literature bulk synthesis. ${ }^{3}$

Although through-wall mass transport is limiting, it is also enabling. The liquid feed into the reactor is trivial, requiring only a single-phase input. The outlet stream is not supersaturated with oxygen, and the assay of oxygenated solvent is low. In addition, the applied pressure is not high, and the pressure chamber is separated from the reaction mixture by the MCF wall, meaning the pressure chamber itself, while full of oxygen, represents no reactive chemical hazard. The ready availability of MCFs means that this methodology can be widely applied, and the advantages inherent in the capillaries suggest attractive applications such as wastewater treatment and other areas of singlet oxygen research.

Microfluidic devices are commonly manufactured using silicone polymers such as polydimethylsiloxane (PDMS), which exhibit gas permeability. The work presented herein suggests that FEP MCFs provide clear advantages over PDMS for use as substrates in microfluidic reaction systems. Key advantages include the ease in fabricating long lengths of MCFs and the high resistance to most chemical reagents and solvents. Moreover, PDMS is ill-suited for use in dye production because nonpolar small molecules readily absorb into PDMS, losing their reactivity and blocking light from the reaction.

In conclusion, it is clear that through-wall mass transport of oxygen represents a facile and safe reactor modality for singlet oxygen photo-oxidations. The ease of use of the described microcapillary film approach for reaction scaleout suggests that this may be an advantageous system for the large-scale use of singlet oxygen.

\section{ASSOCIATED CONTENT}

\section{S Supporting Information}

Experimental details; unitary kinetic equations for chemically sensitized singlet oxygen photo-oxidation; GC calibration data for $\alpha$-terpinene, ascaridole, and p-cymene; and experimental conditions used to synthesize ascaridole in MCFs. This material is available free of charge via the Internet at http://pubs.acs.org.

\section{AUTHOR INFORMATION}

\section{Corresponding Author}

*E-mail: andrew.demello@chem.ethz.ch (A.J.dM.), robert. wootton@chem.ethz.ch (R.C.R.W.).

\section{Author Contributions}

The manuscript was written through contributions of all authors. All authors have given approval to the final version of the manuscript.

Notes

The authors declare no competing financial interest.

\section{ACKNOWLEDGMENTS}

The authors acknowledge Ján Kovacovic for help with highpressure systems, Ioannis Lignos for SEM images, Claire Stanley for the graphical abstract, and Eleanor Bonnist for data regarding ascaridole reaction yields.

\section{ABBREVIATIONS}

ETFE, ethylene tetrafluoroethylene; FEP, fluorinated ethylene propylene; FID, flame ionization detector; GC, gas chromatography; HPLC, high performance liquid chromatography; I.D, inner diameter; LED, light-emitting diode; MCFs, microcapillary films; NMR, nuclear magnetic resonance; O.D, outer diameter; PEEK, polyether ether ketone; PFA, perfluoroalkoxy; Sens, sensitizer dye; Subs, substrate molecule

\section{REFERENCES}

(1) Kruft, B. I.; Greer, A. Photosensitization reactions in vitro and in vivo. Photochem. Photobiol. 2011, 87, 1204-1213.

(2) Wainwright, M. Photodynamic medicine and infection control. J. Antimicrob. Chemother. 2012, 67, 787-788.

(3) Wootton, R. C. R.; Fortt, R.; deMello, A. J. A Microfabricated nanoreactor for safe, continuous generation and use of singlet oxygen. Org. Process Res. Dev. 2002, 6, 187-189.

(4) Takeshita, H.; Hatsui, T. Sensitized photoreduction of dioxetanes to cis-1,2-glycols: Solvent and sensitizer dependencies on the singlet oxygen oxidation. J. Org. Chem. 1978, 43, 3080-3083.

(5) Protti, S.; Dondi, D.; Fagnoni, M.; Albini, A. Photochemistry in synthesis: Where, when, and why. Pure Appl. Chem. 2007, 79 (11), 1929-1938.

(6) Schenc̀k, G. O. Aufgaben und Möglichkeiten der präparativen Strahlenchemie. Angew. Chem. 1957, 69, 579-599.

(7) Grossmann, N.; Winnig, B.; Weise, A.; Fanghanel, E. Azomethinfarbstoffe - Sensibilisatoren, Löscher und Reaktionspartner für Singulettsauerstoff. J. Prakt. Chem. 1987, 329, 767-774. 
(8) Nonell, S.; Gonzalez, M.; Trull, F. R. 1H-Phenalen-1-one-sulfonic acid: An extremely efficient singlet molecular oxygen sensitizer for aqueous media. Afinidad 1993, 50, 445-450.

(9) Yasuike, M.; Yamaoka, T.; Ohno, O.; Sakuragi, M.; Ichimura, K. Singlet oxygen generation by tetrabenzoporphyrins as photosensitizer. Inorg. Chim. Acta 1991, 184, 191-195.

(10) Coyle, E. E.; Oelgemoller, M. Micro-photochemistry: photochemistry in microstructured reactors. The new photochemistry of the future? Photochem. Photobiol. Sci. 2008, 7, 1313-1322.

(11) Mills, P. L.; Quiram, D. J.; Ryley, J. F. Microreactor technology and process miniaturization for catalytic reactions-A perspective on recent developments and emerging technologies. Chem. Eng. Sci. 2007, 62, 6992-7010.

(12) Matsushita, Y.; Ohba, N.; Kumada, S.; Suzuki, T.; Ichimura, T. Photocatalytic $N$-alkylation of benzylamine in microreactors. Catal. Commun. 2007, 8, 2194-2197.

(13) Lévesque, F.; Seeberger, P. H. Continuous-flow synthesis of the anti-malaria drug artemisinin. Angew. Chem., Int. Ed. 2012, 51, 17061709.

(14) Wang, X.; Yong, Y. M.; Fan, P.; Yu, G. Z.; Yang, C.; Mao, Z. S. Flow regime transition for cocurrent gas-liquid flow in micro-channels. Chem. Eng. Sci. 2012, 69, 578-586.

(15) Hallmark, B.; Mackley, M. R.; Gadala-Maria, F. Hollow microcapillary arrays in thin plastic films. Adv. Eng. Mater. 2005, 7, 545-547.

(16) Edwards, A. D.; Reis, N. M.; Slater, N. K. H.; Mackley, M. R. A simple device for multiplex ELISA made from melt-extruded plastic microcapillary film. Lab Chip 2011, 11, 4267-4273.

(17) Dorfling, C.; Hornung, C. H.; Hallmark, B.; Beaumont, R. J. J.; Fovargue, H.; Mackley, M. R. The experimental response and modelling of a solar heat collector fabricated from plastic microcapillary films. Solar Energy Mater. Sol. Cells 2010, 94, 1207-1221.

(18) Darton, N. J.; Reis, N. M.; Mackley, M. R.; Slater, N. K. H. Fast cation-exchange separation of proteins in a plastic microcapillary disc. J. Chromatogr., A 2011, 1218, 1409-1415.

(19) Hornung, C. H.; Hallmark, B.; Baumann, M.; Baxendale, I. R.; Ley, S. V.; Hester, P.; Clayton, P.; Mackley, M. R. Multiple microcapillary reactor for organic synthesis. Ind. Eng. Chem. Res. 2010, 49, 4576-4582.

(20) Extrand, C. W.; Monson, L. Gas permeation resistance of a perfluoroalkoxy-tetrafluoroethylene copolymer. J. Appl. Polym. Sci. 2006, 100, 2122-2125.

(21) Halpern, A. Ascaridole in chenopodium oil. IV. The synthesis of ascaridole. J. Am. Pharm. Assoc. 1951, 40, 68-71.

(22) Hatzakis, E.; Opsenica, I.; Solaja, B. A.; Stratakis, M. Synthesis of novel polar derivatives of the antimalarial endoperoxides ascaridole and dihydroascaridole. ARKIVOC 2007, 8, 124-135.

(23) DeRosa, M. C.; Crutchley, R. J. Photosensitized singlet oxygen and its applications. Coord. Chem. Rev. 2002, 233-234, 351-371.

(24) Kreutz, J. E.; Shukhaev, A.; Du, W.; Druskin, S.; Daugulis, O.; Ismagilov, R. F. Evolution of catalysts directed by genetic algorithms in a plug-based microfluidic device tested with oxidation of methane by oxygen. J. Am. Chem. Soc. 2010, 132, 3128-3132.

(25) Kearns, D. R. Physical and chemical properties of singlet molecular oxygen. Chem. Rev. 1971, 71, 395-427.

(26) Foote, C. S. Photosensitized oxygenations and the role of singlet oxygen. Acc. Chem. Res. 1968, 1, 104-110.

(27) Rudbäck, J.; Bergström, M. A.; Börje, A.; Nilsson, U.; Karlberg, A.-T. $\alpha$-Terpinene, an antioxidant in tea tree oil, autoxidizes rapidly to skin allergens on air exposure. Chem. Res. Toxicol. 2012, 25, 713-721. 